\title{
Sustainable Transportation Systems to Improve Road Safety Situation \\ ${ }^{* 1}$ Anuj Sharma, ${ }^{2}$ Vimal Gahlot, ${ }^{3}$ T.K.Rao, ${ }^{4}$ P.D.Pachpor \\ ${ }^{1,3,4}$ Ramdeobaba College of Engineering and Management, Nagpur \\ ${ }^{2}$ Centre for Research \& Sustainable Development, Bikaner \\ Email: sharmaak@rknec.edu,gahlotv@rediffmail.com,raotk@rknec.edu,pachporpd@rknec.edu
}

Received: 20th November 2019, Accepted: 10th February 2020, Published: 29th February 2020

\begin{abstract}
Road safety is a very serious problem all across the world with 1.3 million people getting fatal injuries. Around 1.5 lakhs people die on Indian Roads with a rate of one death every 4 minutes. The contribution of vulnerable road users group is around $60 \%$ at national level. Along with the safety issue, sustainability, sustainable transportation and sustainable environment are the burning areas of discussion at present. The subject matters related to the meaning, assessment and realization of safe and sustainable transportation are discussed in this paper. The important concerns are various definitions of sustainability, the problems considered under sustainability, different perceptions, assessing sustainability and impact of various transport mode on sustainability. Now the broad areas covered while defining sustainable systems include ecological balance, social welfare and equity and health issues as well. Discrete scientific solutions may not be satisfactory for solving sustainability issues. How the transportation system may be made safe and sustainable through proper integration is the subject matter of the present paper.
\end{abstract}

\section{Keywords}

Road Safety, Sustainable, Integrated, BRT, PRT

\section{Introduction}

The issue of accident is a very grave in highway transportation due to composite flow pattern of traffic, presence of mixed traffic along with most vulnerable group. The accident leads to loss of life and property thus affect the GDP of the nation. The traffic engineers have to accept a big duty of providing safe traffic movements to all road users and ensure their safety. Road accidents cannot be totally prevented but by suitable traffic engineering and management, the accident rates may be reduced slightly but it may not be sustainable. India signed Brasilia declaration in 2015 and committed to reduce the road accidents and fatality by half. But so far the fall in accident rate is not seen. Around 147913 people died on Indian roads in 2017 against 150785 in 2016. [3] This data is not encouraging, which is further spoiled by road fatality figure of the first quarter of 2018 which shows $1.68 \%$ rise over the corresponding previous year quarter. A heterogeneous traffic mix that includes high-speed vehicles sharing the road space with vulnerable road users as well as unsafe road infrastructure and vehicles that are in poor condition all contribute to the high fatality rates seen on India's roads.

Fear about sustainability is imbedded in the growing awareness that human activities have substantial environmental impacts that can enact social, ecological and economical costs. Global air pollution, the durable effects of manufactured toxins, degraded natural resources such as fresh water and fisheries, and the crossborder nature of many environmental problems all highlight the need to view human impacts from a broad perspective. Integrated nature of human activities and therefore the need to coordinate planning among different sectors, and groups can probably be thought of a progress towards sustainability.

Many economists anticipated that improved mobility provides net economic benefits. But now many researches indicate that beyond a particular level more number of motor vehicles can have negative impacts on impacts on economy as the vehicle use inflicts external costs.

The concept of sustainability accepts that each mode of travel can be useful, and attempts to create balanced systems that use each mode for what it does best. Improvement in all modes therefore can be useful and not the new modes only. Support to public transportation by improving walking and cycling facilities and restricting automobile travel in congested area can be beneficial.

Simple sustainability indicator for transportation systems are : fuel consumption and $\mathrm{CO}_{2}$ emission should be less, vehicle pollution should be less, high mass rapid transit ridership is better, less traffic crash injuries and death is better, land consumption for transport is better,

\section{Methodology}

The following methodology was adapted for the study:

(i) Network selection for the study

(ii) Data collection along with the photographs for unsafe practices by road users

(iii) Identifying problems related with design, enforcements, road user behaviour and other unsustainable practices. 
(iv) Analysing the data and suggesting measures to improve safety situation

(v) Recommendation for sustainable transportation system.

Unsafe Practices

There are certain issues related with design, enforcement or road behaviour which makes it very unsafe for movement. Some of the issues which are responsible for unsafe situations are discussed below:

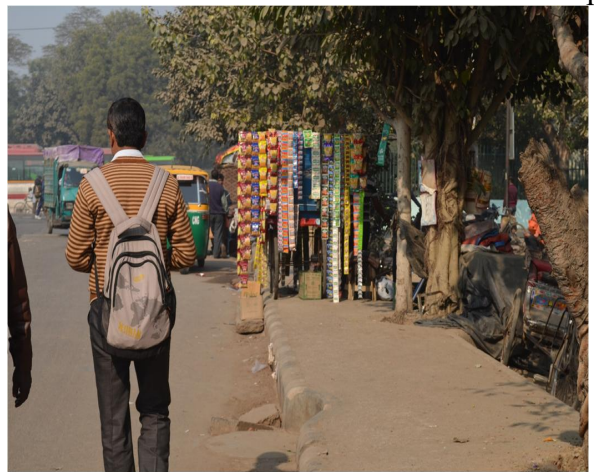

Fig.1: Footpath Encroachment

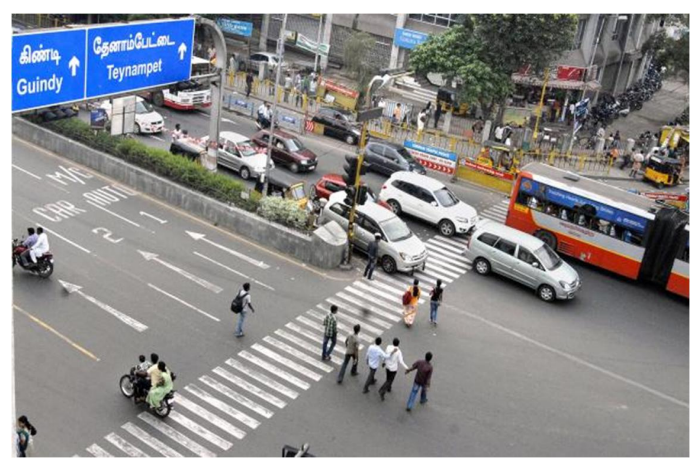

Fig.2: Junction Crossing

Footpath encroachment as can be seen in figl is very common situation in all Indian cities, which compels the road users to use carriageway dangerously. Design of pedestrian crossing as seen in fig 2 is again very common in Indian scenario, which makes the pedestrian to cross the long zebra crossings without any refugee island.
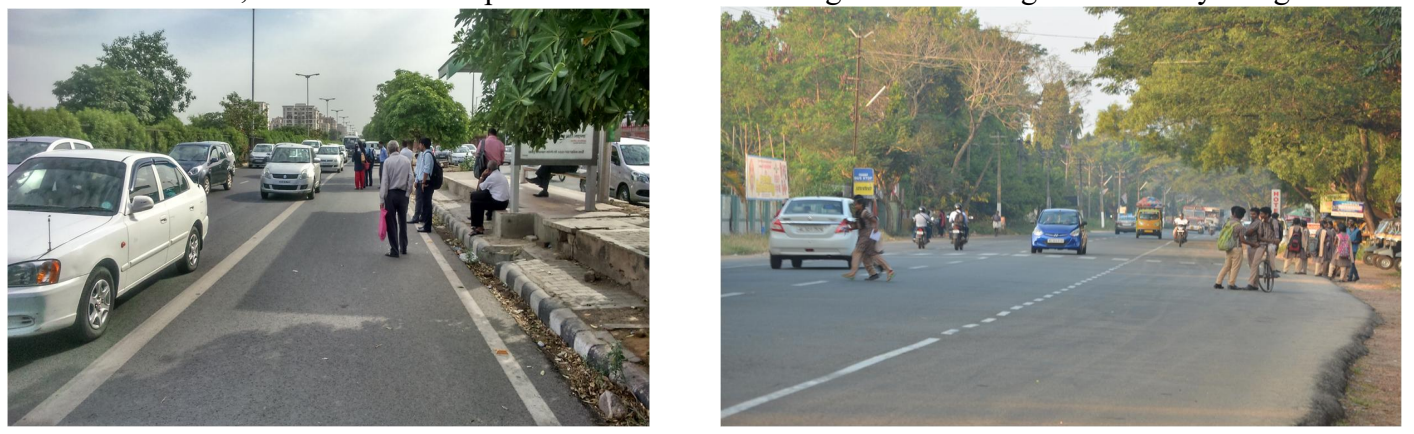

Fig.3: Absence of Bus Bays

Absence of properly designed bus stops are dangerous for the commuters waiting on carriageway for bus arrival and school kids playing on carriageway while waiting for their buses.
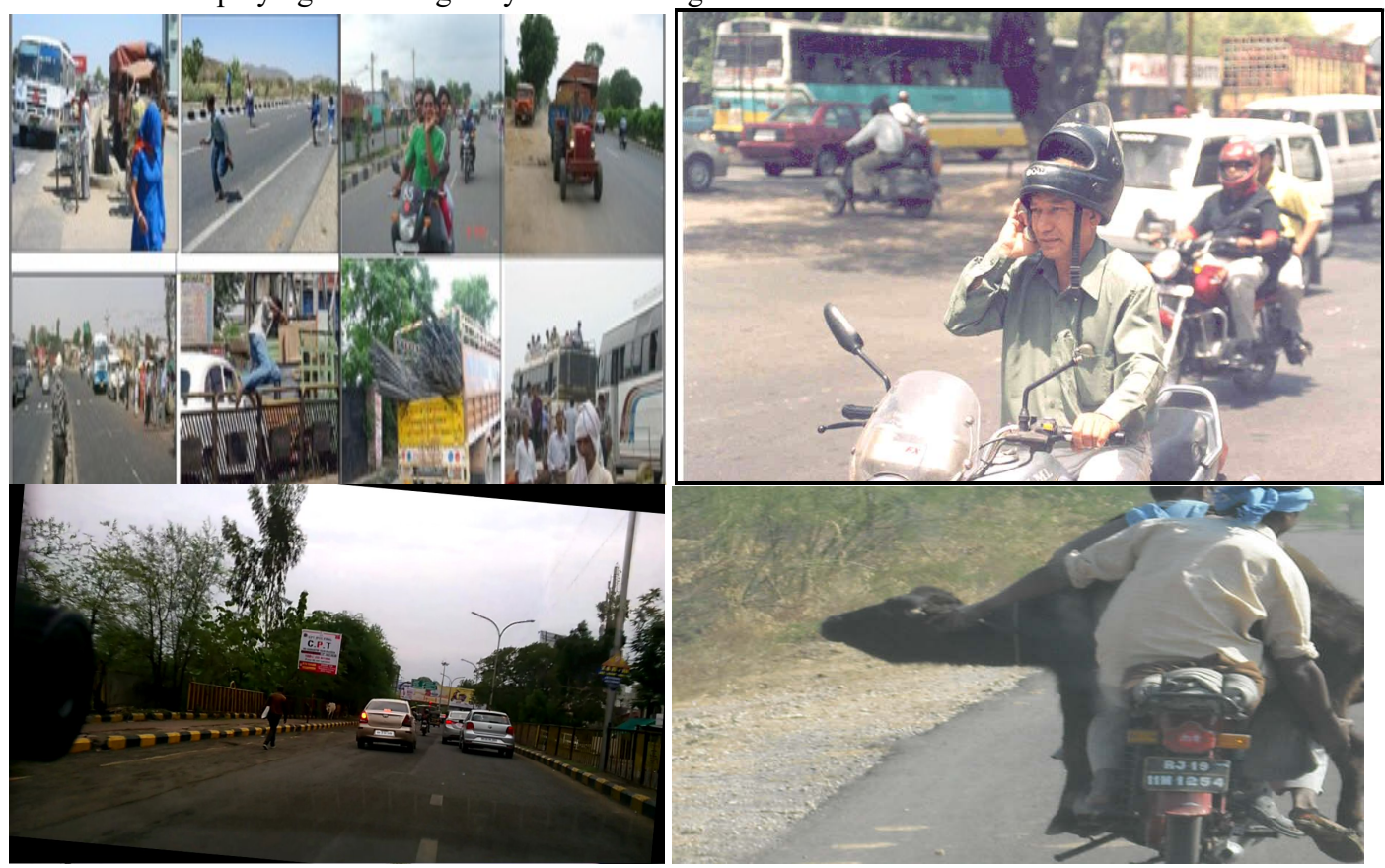

Fig.4: Road Users' Behaviour 
The road user's behaviour is a serious issue as far as road safety is concerned.[7] More than 90\% accidents take place because of unexpected behaviour of the road users. Jumping very high median fencing, use of mobile phone, improper use of the motor vehicles, walking on carriageway while footpaths are available, etc. are very big issue of road traffic safety.
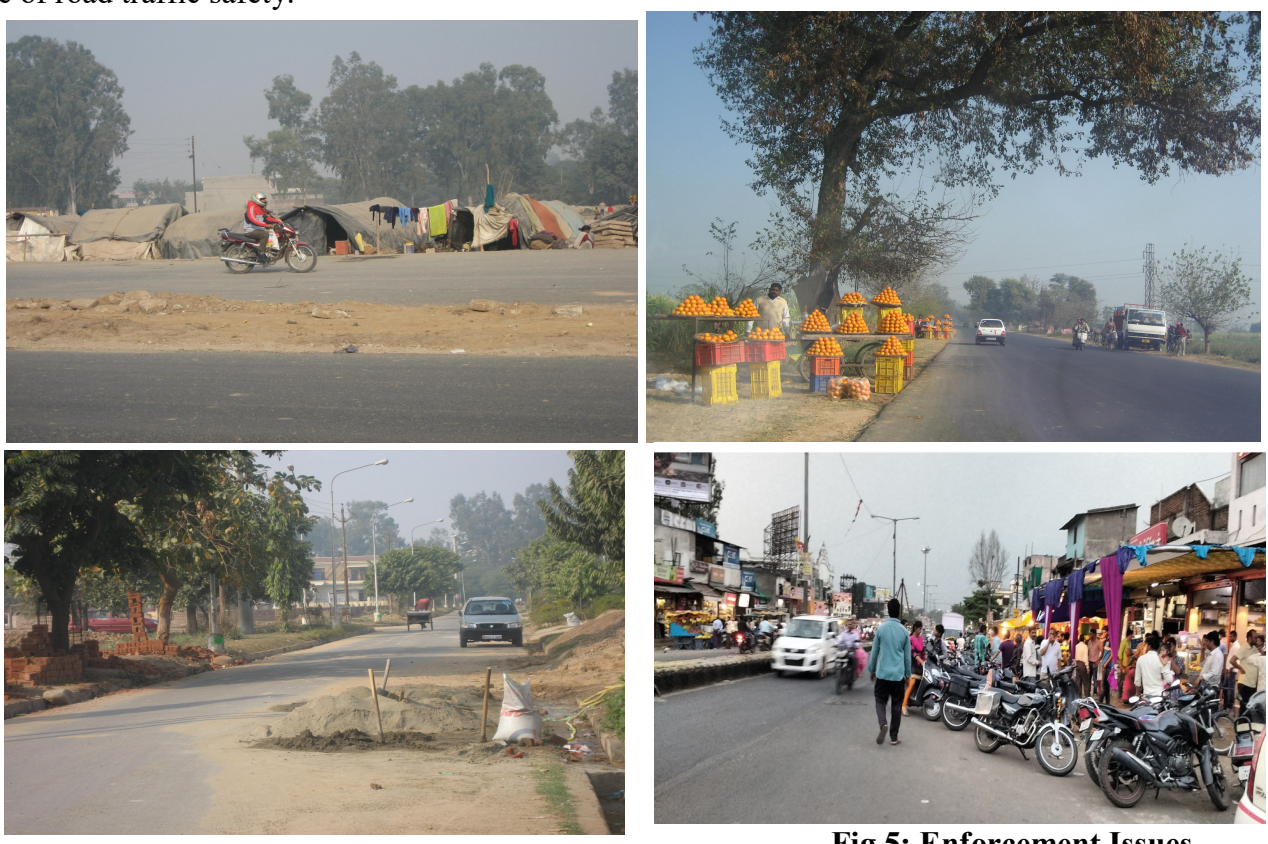

Fig.5: Enforcement Issues

The lack of enforcement measures is also responsible for unsafe situations on roads. People living anywhere on slums very close to shoulder of the roads, selling the goods on shoulders, dumping the construction materials on roads, parking the vehicles on right of the middle of the carriageway, fearlessly moving in wrong direction against the traffic and many such enforcement issues create very unsafe situation for the other road users.
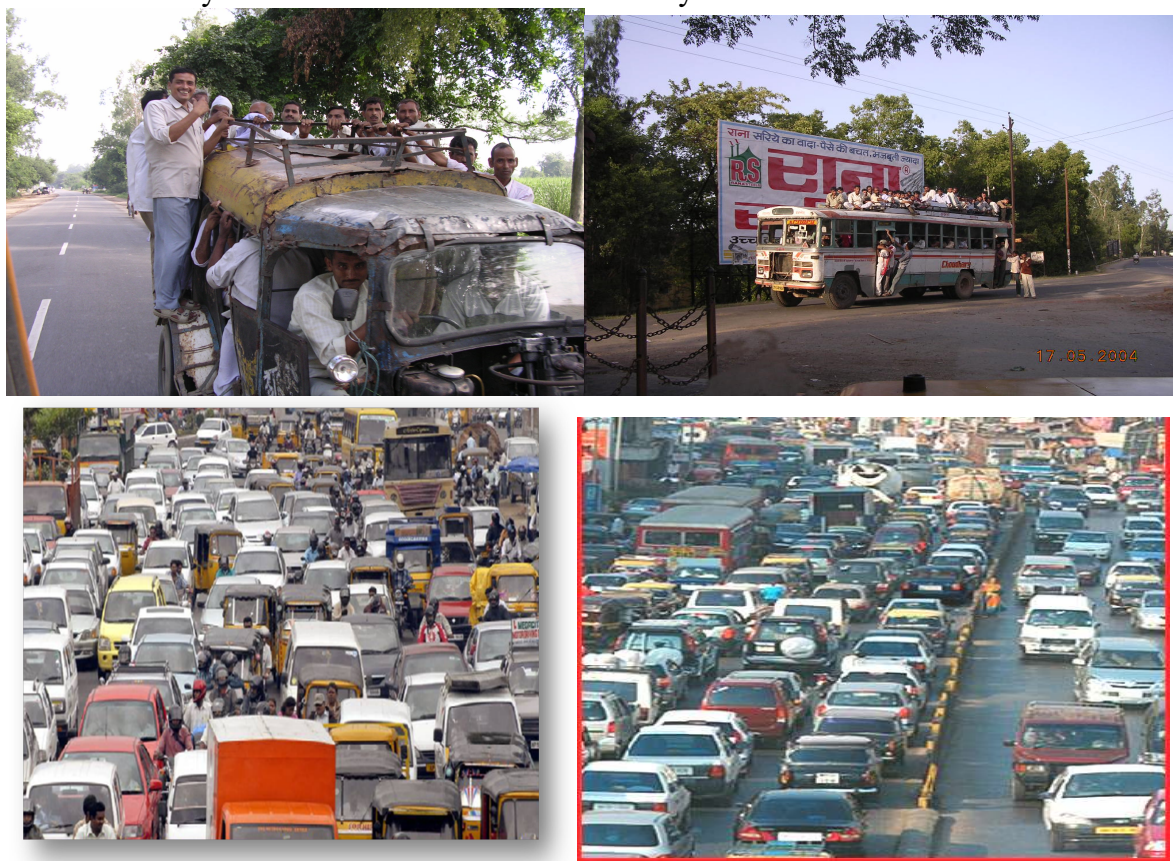

Fig.6: Insufficient Public Transportation

Insufficient Public transport or improperly planned public transportation network are also responsible for unsafe movements on roads. This not only enhances the probability of accidents but also creates severe health issues mental stress, depression, breathing problems, asthmatic problems and serious environmental problems.

Sustainable Transportation System

A sustainable transport system should provide access to people, places, goods, and services in an environmentally responsible, socially acceptable, and economically viable manner.[2] 
People have proposed changes in planning, management and technology for building a transportation system which will be safe and sustainable. The solution should be economically viable, environmentally justifiable and socially acceptable.

There are conflicts involved when we talk of adopting sustainable solutions.[5] Profit of energy producing company and the region will be reduced if we talk of conservation of energy. Strategies are required to compensate for the loser, and allow them the transition period to shift toward sustainable business opportunity.

The introduction of sustainable policies will have serious implications on transportation industries like petroleum and automobile.

\section{Some Sustainable Transport Systems}

\section{Bus Rapid Transit System}

Bus rapid transit system, which is a bus based transit system, is designed to improve the capacity and reliability of bus transport.[4] In this system the buses operate on dedicated lanes and priorities are given to buses when it cross the other traffic streams at intersections. BRT aims to combine the capacity and speed of a metro with the flexibility, lower cost and simplicity of a bus system. Bus running on some alternative fuel will also make it environmentally sustainable.
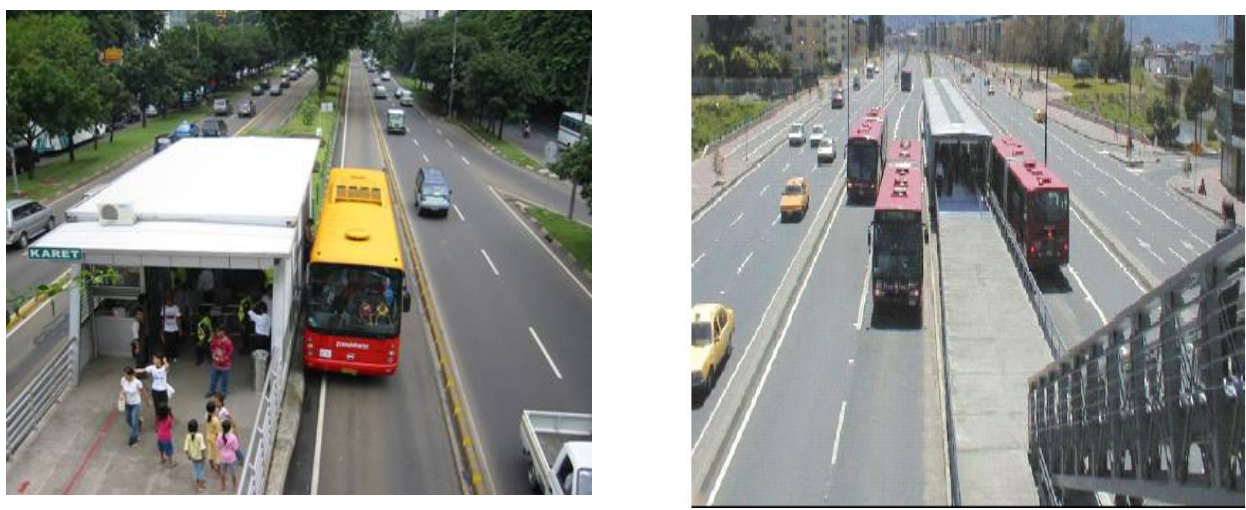

Fig.7: Well Designed Bus Rapid Transit

Personal Rapid Transit System [1]

Personal rapid transit (PRT), also referred to as pod car, is a public-transport mode which uses automated vehicles on specially built guide ways.

The components of PRT are small fully automated battery-powered electric vehicles with zero on-site emissions, light, flexible, aesthetic guide ways and stations with lower cost.[6] The controls are such that you don't wait for vehicles rather vehicles wait for you, no transfers and no routes to memorize. The characteristics of PRT are that it is very efficient, sustainable, reliable, attractive to the users, inexpensive and easy to install. PRT can run with a speed of 40-80 kmph and it can be used as a feeder to major transport corridor. PRT comes under one of the proven way to save the earth.
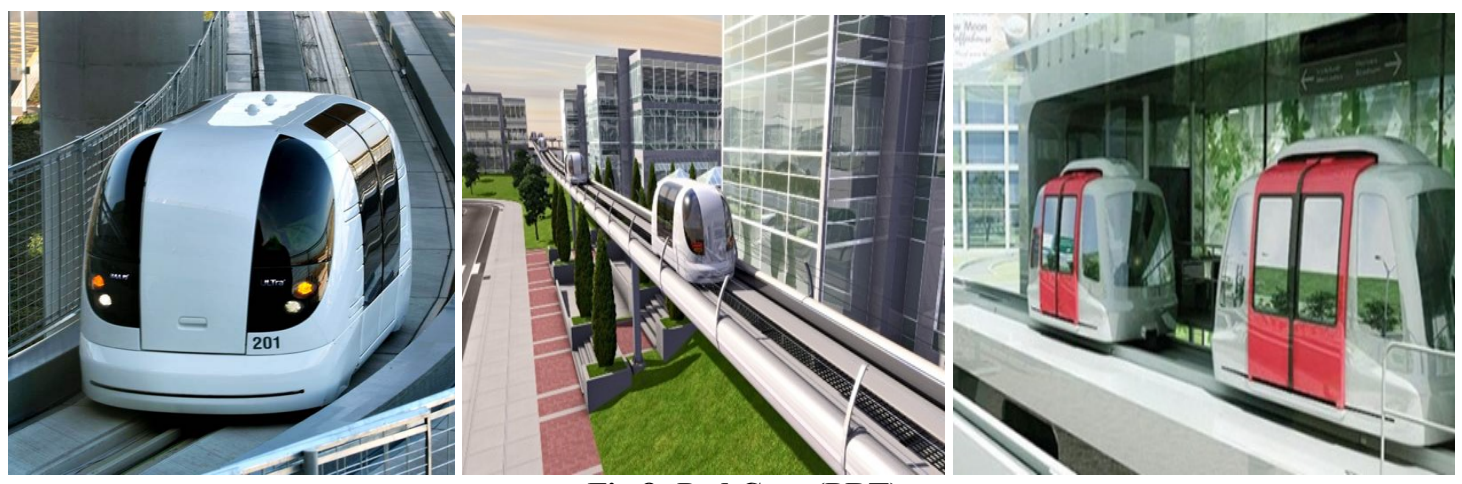

Fig.8: Pod Cars (PRT)

\section{Measure to Improve Public Transportation}

It is very important that public should be attracted to use the public transportation facilities. There are certain measures which are required to integrate the various modes, so that this aim can be achieved.[8] Some of the measures are:

1. Well-designed frontage zones in residential and commercial areas for pedestrians and cyclists.

2. Attractive and safe pedestrian only zones should be made available all across the urban areas. 
3. Well maintained footpath of sufficient width should be provided wherever required.

4. Well-designed street furniture specially waiting areas foe pedestrians and cyclist should be provided.

5. Attractive and aesthetically pleasant pedestrian over bridges should be provided depending on pedestrian traffic volume.

6. Hawker zones should be designated rather than permitting them occupy the space on street.

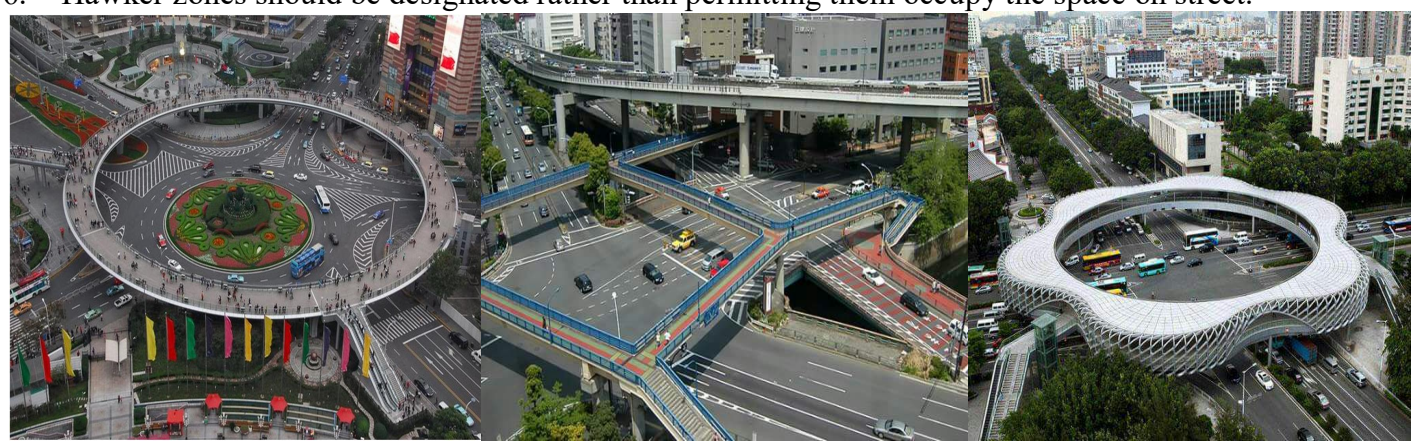

Fig.9: Some Well-designed Pedestrian Over Passes

\section{Need of Integrated Transportation System}

To achieve the goal of a sustainable transportation system, the integration of various modes is required. The various modes of integrated transport systems are:

- $\quad$ Public Transport (PT) Modes includes Metro, Monorail \& BRTS, Medium \& Mini Size Bus

- Para Transit Modes includes Van/Mini-Vans, Taxi/Share Taxi, Dial-a-ride Taxi/ Radio Taxi, Auto Rickshaw

- Non-Motorized Transport (NMT) Modes includes Pedy Cabs/Cycle Rickshaw, Bicycle

The below mentioned are the reasons why we need integration of transportation system"?

- For due patronage to Mass Rapid Transit System (MRTS) in terms of ridership.

- For door-to-door service

- For reduction in travel time

- To decrease the out pocket cost

- Providing services to new areas or new communities and to more people

- To enhance comfort level and safety to commuters \& to eliminate wasteful duplication

- To increase the desirable modal share

- To provide better service to existing and future demand

- To reduce the air pollution

\section{Results and Discussion}

From the case studies of different urban roads in India, the following observations were made:

i. Footpath encroachment by vendor are a common feature.

ii. Design of junction crossing for pedestrians are ill designed.

iii. Absence of bus-bays were noticed at most of the locations.

iv. Illegal parking on carriage-way by road users are very common.

v. Unacceptable behaviour by road users like jumping the median, use of mobile phone while driving, movement in wrong direction etc. were noticed.

vi. Lack of public transportation system creates traffic chaos, congestion and unsustainable movement by the people.

\section{Conclusions}

Many questions are raised when we talk about sustainable transportation systems. It is very important to define the goals and objectives clearly before the planning process starts. It needs the integrated thinking in terms of economic, social and environmental impacts. Sustainable transportation planning should increase economic efficiency, diminish resource depletion and dangerous environmental influences, and improve mobility for nondrivers.

Convincing the people to change the attitude and behaviour in terms of their choice of travel mode is the need of the hour. For sustainable development people should be forced to use public transportation systems. Due patronage should be given to non-motorized transport in transport planning. Use of public transportation system can be improved when facilities to pedestrians are attractive and safe. Also safety measures for all road users should be included in planning stages for safe and sustainable transportation of people and goods. 


\section{References}

1. Anuj Kumar sharma, Ankit suman, Shreevardhan Poddar "Personal Rapid Transit- an innovative and sustainable transport system, OSR Journal of Mechanical and Civil Engineering (IOSR-JMCE), e-ISSN: 22781684, p-ISSN: 2320-334 PP 67, 2014

2. David L, Greene, Michael Wegener "Sustainable Transport", Journal of Transport Geography, Volume 5, Issue 3, September 1997, Pages 177-190

3. http://www.indiaenvironmentportal.org.in/files/file/road\%20accidents\%20in\%20India\%202017.pdf

4. https://en.wikipedia.org/wiki/Bus_rapid_transit

5. https://en.wikipedia.org/wiki/Sustainable_transport

6. https://www.railway-technology.com/projects/personal-rapid-transit/

7. Marjan P.Hagenzieker, Jacques J.F.Commandeur ,Frits D.Bijleveld, "The history of road safety research: A quantitative approach" Transportation Research Part F: Traffic Psychology and Behaviour, Volume 25, Part B, July 2014, Pages 150-162

8. Urban Transportation by D. J. Victor \& S. Ponnuswamy 